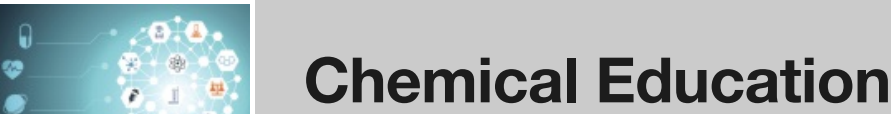

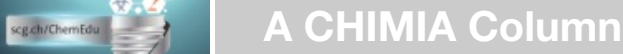 \\ Topics for Teaching: Elemental Stories
}

\section{The Short and Sad Life of Helvetium - an Element that Never Was}

\section{Edwin C. Constable*}

${ }^{*}$ Correspondence: Prof. E. C. Constable, E-mail: edwin.constable@unibas.ch, Department of Chemistry, University of Basel, BPR 1096, Mattenstrasse 24a, $\mathrm{CH}-4058$ Basel

Abstract: The highways and by-ways of chemical history are littered with discarded claims for the identification of new elements. This is the story of one, or possibly two, such elements.

Keywords: Anglo-helvetium · Astatine · Element 85 .

Helvetium · Periodic table

Francium, polonium, americium, germanium, thulium, europium, copper, scandium ... there is a long list of elements named after countries or continents. [1,2] "Where", asks the Swiss chemist "is our element?" The answer to that question brings us to the short and sad life of the element helvetium.

The years between 1869, when Dmitrii Ivanovich Mendeleev formulated his periodic table, and the demonstration of the physical basis of the atomic number by Henry Mosely in 1913 were a kind of Wild West for the element hunters. Scarcely a month went by without claims for the isolation or identification of a new element. ${ }^{[1,2]}$ Equally frequent was the demonstration that these new elements were either mixtures of known elements or of additional unknown elements! This spiral of discovery came to an end with Moseley and the periodic table took on a familiar form with well-established positions for elements not yet discovered. Although it remained open season for the transuranium elements, by the 1930 's, the only vacancies for elements in the main part of the periodic table were for those with atomic numbers 61,85 and 87. By 1939, francium (element 87 ) had been discovered by Marguerite Perey and named after her native France ${ }^{[3 a, b]}$ whereas promethium (element 61) had to wait until the end of the second World War. Our story concerns the element with atomic number 85. ${ }^{[1,2,4,5]}$

Element 85 was expected to be a member of the halogens (Group 17) but the description ekaiodine was apparently only introduced in the $8^{\text {th }}$ edition of Mendeleev's 'Principles of Chemistry' in 1906. ${ }^{[6]}$ Early claims for the isolation of element 85 from monazite sand by conventional methods were discredited ${ }^{[5]}$ and it became clear that the hunt for new elements would be like that for Friday in Robinson Crusoe - it would be first identified by its footprints, or more precisely by the evidence of its own radioactive decay or the decay of its precursor.

Now is the time for Walter Minder to come on stage. Minder had been director of the Radium Institute at the Inselspital, associated with the University of Bern, since 1931 and he investigated the decay of ${ }^{222} \mathrm{Rn}$. He demonstrated that the growth of $\beta$-activity was about $50 \%$ greater than predicted for the known decay products ${ }^{214} \mathrm{~Pb}(\mathrm{Ra} \mathrm{B})$ and ${ }^{214} \mathrm{Bi}(\mathrm{Ra} \mathrm{C})$ (Fig. 1). He interpreted this in terms of the $\beta$-decay of the first daughter product ${ }^{219} \mathrm{Po}(\mathrm{Ra} \mathrm{A})$ according to Scheme 1a. Minder announced his discovery thus, "A $\beta$-decay of Ra A leads to the previously unknown element 85. It is proposed that it should be called helvetium (Hv). Chemical reactions proving the existence of this element are absent, but these are not initially absolutely mandatory". ${ }^{77]}$ Although his discovery was reported in Nature "Dr Minder has named the new element 'helvetium' in honour of his country", ${ }^{[8]}$ the response of the scientific community to the announcement of a new element was muted, not unreasonably considering the turmoil caused by the developing global conflict.

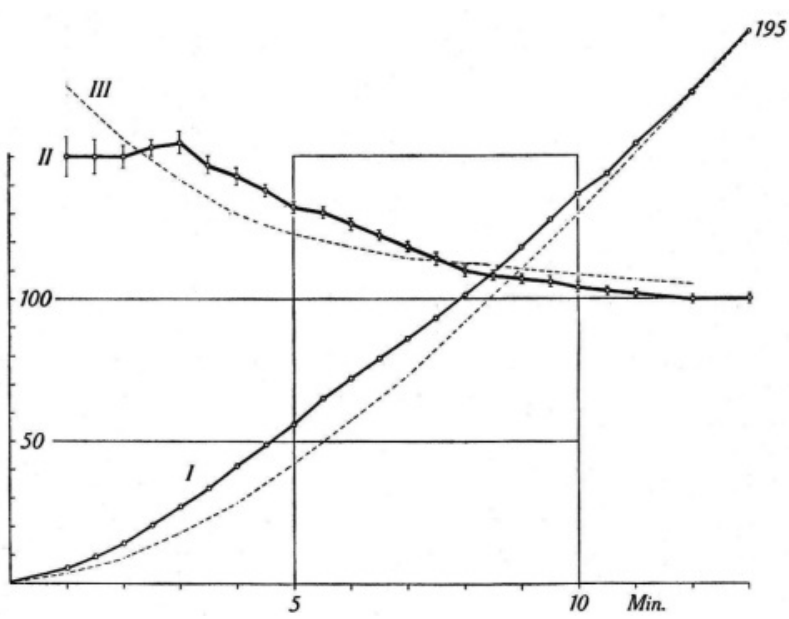

Fig. 1. The $\beta$-emissions that led Minder to propose the formation of element 85 in the radioactive decay of ${ }^{218} \mathrm{Po}(\mathrm{Ra} A)^{[7]}$ (http://www.eperiodica.ch http://doi.org/10.5169/sea/s-111054). The figure caption states 'Calculated and measured temporal increase of the $\beta$-radiation of the radium emanation and its decay products for the first 13 minutes'. Top: Ratio of the measured increase to the calculated increase (II). Calculated ratio if $\beta$-radiation of $R a A$ is assumed, the ionization of which is $15 \%$ of Ra B (III) (reproduced with permission of the Swiss Physical Society).

a) ${ }_{84}^{219} \mathrm{Po} \stackrel{-\beta^{-}}{\longrightarrow}{ }_{85}^{219} \mathrm{Hv}$

b) ${ }_{84}^{216} \mathrm{Po} \stackrel{-\beta^{-}}{\longrightarrow}{ }_{85}^{216} \mathrm{Ah}$

Scheme 1. (a) The $\beta$-decay of ${ }^{219} \mathrm{Po}$ (Ra A) proposed by Minder in 1940 for the formation of ${ }^{219} \mathrm{Hv}$ (element 85 , helvetium) ${ }^{[7]}$ and (b) the $\beta$-decay of ${ }^{216} \mathrm{Po}$ (Th A) proposed by Minder and Leigh-Smith in 1942 for the formation of ${ }^{216} \mathrm{Ah}$ (element 85 , anglo-helvetium). ${ }^{[11]}$

In September 1942, Berta Karlik and Traude Bernert from the Institute for Radium Research in Vienna brought these results into question. "To sum up, it can be stated that there are no [positive] indications in our attempts to find a soft $\beta$-radiation from 
$\mathrm{Ra} \mathrm{A}$ of the order of magnitude of the radiation level specified by MINDER and thus no proven existence of the element 85 in the natural decay series". ${ }^{[9]}$

In the meantime, Minder had acquired a beautiful coworker ("eine sehr hübsche Dame"[10]), Dr Alice Leigh-Smith. Alice Leigh-Smith was born in Croatia and had commenced her studies in radiochemistry with Marie Curie in Paris in 1932. In 1933, she married Philip Leigh-Smith, a British diplomat and first cousin once-removed to Florence Nightingale, and by 1942 an attaché at the British Embassy in Bern. Minder and Leigh-Smith reinvestigated the decay of radon, this time selecting thoron, ${ }^{220} \mathrm{Rn}$, as the starting material. The primary decay product of ${ }^{220} \mathrm{Rn}$ is ${ }^{216} \mathrm{Po}$ (Th A) and it was this material that Minder and Leigh-Smith collected. Recognizing that element 85 should be a halogen, they sublimed material onto a silver wire and investigated the ionizing radiation from this in a cloud chamber. They observed both $\alpha$ and $\beta$ particle tracks, the former being dominant and corresponding to the major decay pathway to ${ }^{212} \mathrm{~Pb}$ (Th B). Assuming $\beta$-decay of ${ }^{216} \mathrm{Po}$, it should generate isotope 216 of element 85 , which then gives ${ }^{216} \mathrm{Rn}$ by $\beta$-decay. The latter then decays to ${ }^{212} \mathrm{Po}$ by $\alpha$-particle emission. Critical to the claim was the observation of twin $\alpha$-tracks, sometimes accompanied by weaker $\beta$-tracks, from a single point. Somewhat problematic, was the fact that these were in the gas and not localized on the silver wire (Fig. 2). Nevertheless, and for the second time, Minder claimed the identification of element 85 and proposed a new name "As a tribute to the scientific work of our two countries, we propose to name the element 85 'anglohelvetium". ${ }^{[11]}$ The name was not received uncritically, and a correspondent in Nature in 1943 wished to "register a protest at the ungainly name suggested for element 85 by Mrs. A. Leigh-Smith and A. (sic) Minder. The more science has been divorced from the humanities the more has mankind been afflicted by unpleasing words".[12] Once again, his Austrian colleagues Karlik and Bernert were to prove his nemesis; in 1944 they wrote "The attempts by A. Leigh-Smith and W. Minder to incorporate element 85 in the thorium series were repeated, but the results could not be confirmed".[13] A veritable flood of claims, counter-claims and recriminations followed, conducted in both the scientific ${ }^{[14]}$ and the popular press. ${ }^{[2]}$ Scientifically, there was no follow-up from Minder. And so the short life of helvetium came to a close
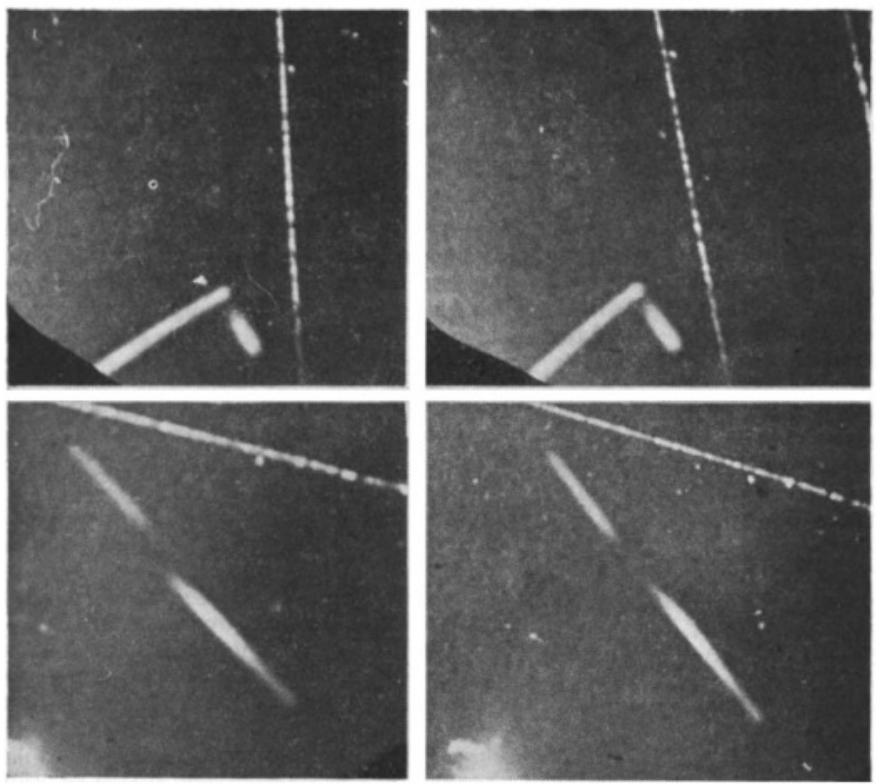

Fig. 2. Minder and Leigh-Smith's stereophotographs showing twin $\alpha$-tracks in the cloud chamber. Unfortunately "owing to the war, films were difficult to obtain, they could not be wasted" they did not document disintegrations also showing the $\beta$-tracks ${ }^{[11]}$ (reproduced with permission).
Leigh-Smith seems to have been more than a scientist, As Minder wrote in 1981, she later "appeared in my institute with a rather thick bundle of Swiss banknotes in her hand and asked me "Would you travel to Berlin for us and find out where the leading atomic physicists from the former Berlin group are now working? You know most of the people personally; it would be of great interest to us".[10]

And what became of the players in our little drama? Walter Minder remained in Bern and was a leading light in medical radiology, becoming Head of the Radiation Protection Section of the Swiss Federal Office of Public Health. He was also politically active in the movement to restrict military use of nuclear energy. He remained convinced of his discovery of element 85 and wrote in 1981 "We were convinced, and I am still today, that we had observed the $\alpha$-radiation of Astatine-216". ${ }^{[10]}$ Alice Leigh-Smith remained a diplomat's wife ${ }^{[15]}$ but continued to press her claims for the identification of element $85 .{ }^{[16]}$ Whilst the story has no heroes or heroines, the real star is element 85 itself. Credit for the synthesis of element 86 is given to Dale Corson, Kenneth McKenzie and Emilio Segré who in 1940 bombarded ${ }^{209} \mathrm{Bi}$ with high energy $\alpha$-particles to obtain the isotope of mass $211,{ }^{[17]}$ and this team later gave the name astatine (Greek $\alpha \sigma \tau \alpha \tau o \zeta$, unstable), symbol At, to the element, ${ }^{[18]}$ with the claim to priority and the name being confirmed by IUPAC in 1949. ${ }^{[19]}$ As a final comment, claims from Horia Hulubei and Yvette Cauchois for the identification of naturally occurring element 85 dating back to 1934 and the independent work of Karlik and Bernert in 1942 and 1943 all appear to have considerable merit and are discussed in detail in ref. [5].

Received: March 29, 2019

[1] E. Scerri, 'A Tale of Seven Elements', OUP, Oxford, 2013

[2] M. Fontani, M. Costa, M. V. Orna, 'The Lost Elements. The Periodic Table's Shadow Side', OUP, Oxford, 2014.

[3] a) M. Perey, C. R. Seances Acad. Sci. 1939, 208, 97; b) M. Perey, J. Phys. Radium 1939, 10, 435

[4] V. D. Nefedov, Yu.V. Norseev, M.A. Toropova, V.A. Khalkin, Usp. Khem. 1968, 37, 193, English version, Russ. Chem. Rev. 1968, 37, 87.

[5] B. F. Thornton, S. C. Burdette, Bull. Hist. Chem. 2010, 35, 86.

[6] H. W. Kirby, 'Gmelin Handbook of Inorganic Chemistry', $8^{\text {th }}$ Edn., System number 8a, Astatine, Springer-Verlag, Berlin, 1985.

[7] W. Minder, Helv. Physica Acta 1940, 13, 144.

[8] Nature 1940, 146, 225.

[9] B. Karlik, T. Bernert, Naturwissenschaften 1942, 30, 685.

[10] W. Minder, 'Geschichte der Radioaktivität', Springer Verlag, Berlin, 1981, p. 1 .

[11] W. Minder, A. Leigh-Smith, Nature 1942, 150, 767.

[12] C. W. Martin, Nature 1943, 151, 309.

[13] B. Karlik, T. Bernert, Z. Phys. 1942, 30, 685.

[14] F. A. Paneth, Nature 1942, 149, 565.

[15] P. Leigh-Smith, 'Ladies in Diplomacy', George G. Harrap \& Co, London, 1965.

[16] A. Leigh-Smith, O. D’Agostino, Rend., Ist. Sanita Pubblica 1947, 10, 523

[17] D. R. Corson, K. R. McKenzie, E. Segré, Phys. Rev. 1940, 57, 459

[18] D. R. Corson, K. R. McKenzie, E. Segré, Nature 1947, 159, 24

[19] Chem. Eng. News 1949, 27, 2996. 